\title{
Media and User Features that Affect Knowledge Sharing Intention and Knowledge Sharing Behaviors on Wechat
}

\author{
Guozhong Li', Hong Jin ${ }^{2}$ and Seong-Taek Park ${ }^{3 *}$ \\ 'Department of Management Science and Information System, Kunming University of Science and Technology, \\ No. 68 Wenchang Road, 121 Street, Kunming, Yunnan Province, 650093, China; misgukchung@nate.com \\ ${ }^{2} \mathrm{~S} c h o o l$ of Business, Jiangxi Normal University, 99 Ziyang Ave Nanchang, \\ Jiangxi, 330022,China; jinhong0238@hanmail.net \\ 32Department of Management Information Systems, 1 Chungdae-ro, Seowon-gu, \\ Cheongju Chungbuk, 28644, South Korea; solpherd@cbnu.ac.kr
}

\begin{abstract}
Objectives: This study aims to shed light on the factors that influence mobile social networking applications (Wechat) users' intention and behaviors to share knowledge from the perspective of both media and psychological features. Methods/Statistical analysis: This research conducted questionnaire survey via online survey company (Wenjuanxing) and 197 samples were collected. Based on the data collected, research model and hypotheses were tested using smart pls 2.0. Internal consistency, convergent validity and discriminant validity were examined that were required in Partial Least Squares (PLS) analysis. Findings: The analytical results of this research show that media features-mobility and interactivity is insignificantly related with the Wechat users' intention to share knowledge. Users' psychological featuresaltruism, sense of self-worth and knowledge self-efficacy were found significantly related with users' Knowledge Sharing Intention (KSI) and Knowledge Sharing Behaviors (KSB). This research empirically examined users' psychological features which were found to be the main factors that drive individuals to participate in the knowledge sharing activities on mobile devices. These findings are particularly significant by having a deep insight into individual's knowledge sharing activities from the perspectives of both media and users' psychological features in the mobile internet era. The results of this research are believed to contribute to the future research on people's new knowledge acquisition patterns. Application/Improvements: The results of this study will provide great benefits to companies or educational institutions with evidences of individual of their information acquisition behaviors in today's mobile internet era.
\end{abstract}

Keywords: Interactivity, Knowledge Self-Efficacy, Knowledge Sharing Behaviors, Mobility, Sense of Self-Worth, Wechat

\section{Introduction}

Wechat is a free instant messaging application based on Smartphone and other mobile devices. Since it first came into the market in 2011, it has rapidly become popular with 549million users covering over $90 \%$ of Chinese Smartphone users by the first season of 2015.

It also provides services such as moments, public accounts, Wechat payments and city services. Wechat has brought us many conveniences in dealing with problems occurred in our work and it also provides us with abundant valuable information. Nowadays people actively take advantages of all fragmented time such as commuting, waiting for other people, before going to sleep or breaks in work to read and share information on Wechat, and this has dramatically changed people's information processing activity via traditional media such as Personal Computer (PC), Television (TV) or newspaper.

For example, "public accounts", which is similar to RSS service, delivers abundant information on special topics in accordance with one's needs. Without spatial and temporary limitation, Wechat users enjoys sharing

${ }^{*}$ Author for correspondence 
these information by sending them to others or published in Moments (one of Wechat service) which could be seen by all of the Wechat friends.

Therefore, this is crucial to figure out the effects of such change in the pattern people acquire knowledge and exploit the value of fragmented time in today's mobile media era. This research considers the necessity to investigate from two perspectives- media features (mobility and interactivity)of Wechat and users' psychological features (altruism, sense of self-worth and self-efficacy)to figure out how these factors drive users to knowledge sharing behaviors on the platform of Wechat.

This research is aiming to empirically test the relationships between the media and users' psychological features and users' KSI and KSB. The results of this research contribute to understanding of the value of fragmentized time in mobile media era; the value of learning with fragmented time; the effects of Wechat media features on users' intention and behavior to share knowledge; the effects of psychological features of Wechat users in KSI and KSB.

We broke this research into the following sections. In section 2, research backgrounds, research approaches, research purposes and contributions were introduced. In section 3 , the related literatures were reviewed. In section 4 , the research model and development of hypotheses for media features and users' psychological features were described. Discussion and conclusions were contained in section 5 and section 6 .

\section{Related Work}

\subsection{Mobility}

Mobility was found to be the critical feature of mobile services 9 and it plays critical roles for the mobile device users in deciding whether to adopt certain services or not 1 .The spatial and temporal dimensions of mobility enable individuals to access information, services or communication without spatial or temporal limitation. Mobility is regarded as the critical advantage of information acquisition activity of Wechat users.

\subsection{Interactivity}

In defines" interactivity, "the extent to which users can participate in modifying the form and content of a mediated environment in real time". Three dimensions of perceived interactivity are perceived control, responsiveness and personalization $[$, 7 .
Previous studies have examined the knowledge sharing in relation to participation and interaction and interactivity plays a crucial role in the success of online marketing In classified interactivity into two forms machine interactivity and person interactivity). Machine interactivity refers to the user- medium communication, and person interactivity refers to the user-user communication via medium.

\subsection{Altruism}

Altruism - a willingness to help others at cost to oneself without an immediate or guaranteed return - is a powerful act. Altruistic behaviors refer to the kindness one provide to others and not expect benefits from them

\subsection{Sense of Self-Worth}

Self-worth is one's attitude towards oneself in satisfying or accepting of oneself for what he or she has achieved or what characteristics he or she possesses. Differences between internal and external contingencies of self-worth has been distinguished in the research by ${ }^{11}$ Moral virtue, family love and support, and God's love are main forms of internal contingencies; physical appearance, outdoing others in competition, academic competence, etc. are main forms of external contingencies.

Self-esteem is defined as overall attitudes toward himself or herself, which is important in the forming of one's self-concept and thus, individuals with higher levels of self-esteem tend to more positively acceptance themselves despite of their disabilities 1 .

\subsection{Knowledge Self-Efficacy}

Knowledge is classified into explicit and tacit. Explicit Knowledge refers to formally and systematically stored information, which is measured and disseminated in a form as a manual or a computer file ${ }^{\text {月 }}$. Tacit knowledge refers to information that is deeply embedded in individuals' mind, is personal and is hard to formalize and communicate. One's experience and creativity are examples of tacit knowledget

Individuals of high self-efficacy are more confident of

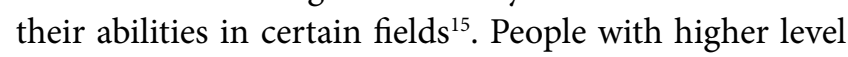
of knowledge self-efficacy tend to believe their knowledge can help others with their work-related problemst Individuals with higher knowledge self-efficacy believe their knowledge benefits others by participating in the virtual community activities. In the online context, 
knowledge sharing behavior can be predicted taking advantage of knowledge sharing self-efficacy ${ }^{17,18}$.

\section{Materials and Methods}

\subsection{Materials}

A questionnaire survey was conducted and totally 197 respondents answered including 34 offline respondents and 163 online respondents. Offline respondents are students from Kunming University of Science and Technology and online students are from different cities in China.

\subsection{Methods}

\subsubsection{Research Models}

Figure 1 depicts our research model. Note that the model consists of two parts of independents variables: the first two variables are features of Wechat media, the other three variables are Wechat users' psychological features.

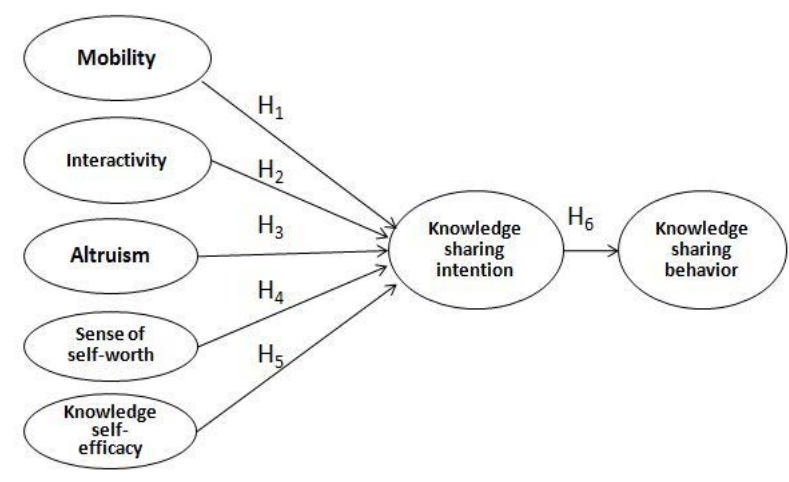

Figure 1. Research model.

\subsubsection{Research Hypotheses}

Mobility means the degree to which a media can provide service without spatial and temporal limitation. In other words, spatial and temporal dimensions of mobility enable individuals to access information, services or communication without spatial or temporal limitation's.

Mobility is the critical factor that drives the users' motivation to use Wechat for knowledge sharing, taking into considerations of the critical role perceived mobility plays in deciding whether to adopt particular mobile services or note, ${ }^{20}$ Therefore, propose the following hypothesis.

$\mathrm{H1}$ : Wechat's mobility is positively related with KSI.

"The extent to which users can participate in modifying the form and content of a mediated environment in real time" is the definition made by Person interactivity means dialogue between individuals-through a medium 7 . Therefore, propose the following hypothesis.

$\mathrm{H} 2$ : Wechat's interactivity is positively related with KSI.

Altruistic individuals don't expect returns for what favors they've done to others ${ }^{2}$, which leads to enhanced satisfaction of outcomes from knowledge sharing activities 3 . Altruistic behavior plays an important role in inducing individuals' intentions to take part in knowledge sharing activities ${ }^{3}$. Thus, altruistic individuals tend to sharing valuable knowledge for other Wechat users. Therefore, propose the following hypothesis.

H3: Wechat user's altruism is positively related with KSI.

Self-worth impacts individuals in forming of their attitudes towards themselves by judging what they achieved and assessing their personal characteristics. A difference between internal and external contingencies of self-worth has been distinguished in the research by ${ }^{11}$.

Self-esteem is defined as overall attitudes toward himself or herself, which is important in the forming of one's self-concept and thus, individuals with higher levels of self-esteem tend to more positively acceptance themselves despite of their disabilities ${ }^{12}$. Therefore, propose the following hypothesis.

H4: Wechat user's sense of self-worth is positively related with KSI.

Explicit Knowledge is measured and disseminated in a form as a manual or a computer file ${ }^{\text {月 }}$, whereas tacit knowledge is deeply embedded in individuals' mind and hard to formalize and communicate. One's experience and creativity are examples of tacit knowledge ${ }^{2}$.

Individuals of high self-efficacy are confident of their abilities in their fields ${ }^{\text {lo }}$, thus they tend to believe their knowledge can help others out of their workrelated problems self-efficacy believe their knowledge benefits others by participating in the virtual community activities. Therefore, propose the following hypothesis.

H5: Wechat user's knowledge self-efficacy is positively related with $\mathrm{KSI}$. 
The Theory of Reasoned Action (TRA) and Theory of planned behavior (TPB) explains that an individual's behaviors come from his or her intentions ${ }^{2}$. Significant relationship were found that exists between an individual's intention and actual behaviors when users participate in the activities of knowledge sharing 25, 26. Therefore, propose the following hypothesis.

H6: Wechat user's KSI is positively related with knowledge sharing behavior.

\section{Results}

\subsection{Measurement Model}

Our research applied smart PLS 2.0 to examine internal consistency, convergent validity and discriminant validity that are required to meet the criteria in PLS analysis.

In Table 1 shows the results of the internal consistency, convergent validity and discriminant validity examination. The internal consistency of constructs was assured by

Table 1. Convergent validity, internal consistency and discriminant validity

\begin{tabular}{|c|c|c|c|c|c|c|c|c|c|c|c|}
\hline \multirow[t]{2}{*}{ Constructs } & \multirow[t]{2}{*}{$\begin{array}{l}\text { Item } \\
\text { Measured }\end{array}$} & \multirow{2}{*}{$\begin{array}{c}\begin{array}{c}\text { Convergent } \\
\text { Validity }\end{array} \\
\text { Outer } \\
\text { Loading }\end{array}$} & \multicolumn{2}{|c|}{$\begin{array}{c}\text { Internal } \\
\text { Consistency }\end{array}$} & \multicolumn{7}{|c|}{ Discriminant Validity } \\
\hline & & & $\begin{array}{l}\text { Composite } \\
\text { Reliability }\end{array}$ & AVE & Alt & Int & KSB & KSE & KSI & Mob & SSW \\
\hline \multirow[t]{6}{*}{ Altruism } & Alt1 & 0.755 & 0.879 & 0.549 & 0.741 & & & & & & \\
\hline & Alt2 & 0.751 & & & & & & & & & \\
\hline & Alt3 & 0.798 & & & & & & & & & \\
\hline & Alt4 & 0.739 & & & & & & & & & \\
\hline & Alt5 & 0.641 & & & & & & & & & \\
\hline & Alt6 & 0.755 & & & & & & & & & \\
\hline \multirow[t]{3}{*}{ Interactivity } & Int1 & 0.851 & 0.846 & 0.648 & 0.646 & 0.805 & & & & & \\
\hline & Int2 & 0.832 & & & & & & & & & \\
\hline & Int3 & 0.726 & & & & & & & & & \\
\hline \multirow{2}{*}{$\begin{array}{l}\text { Knowledge } \\
\text { Sharing } \\
\text { Behavior }\end{array}$} & KSB1 & 0.795 & 0.817 & 0.691 & 0.218 & 0.235 & 0.831 & & & & \\
\hline & KSB2 & 0.865 & & & & & & & & & \\
\hline \multirow{3}{*}{$\begin{array}{l}\text { Knowledge } \\
\text { Self-Efficacy }\end{array}$} & KSE1 & 0.858 & 0.859 & 0.670 & 0.710 & 0.595 & 0.387 & 0.818 & & & \\
\hline & KSE2 & 0.811 & & & & & & & & & \\
\hline & KSE3 & 0.785 & & & & & & & & & \\
\hline \multirow{3}{*}{$\begin{array}{l}\text { Knowledge } \\
\text { Sharing } \\
\text { Intention }\end{array}$} & KSI1 & 0.859 & 0.871 & 0.694 & 0.689 & 0.560 & 0.398 & 0.708 & 0.833 & & \\
\hline & KSI2 & 0.785 & & & & & & & & & \\
\hline & KSI3 & 0.853 & & & & & & & & & \\
\hline \multirow[t]{5}{*}{ Mobility } & Mob1 & 0.792 & 0.894 & 0.627 & 0.665 & 0.620 & 0.284 & 0.548 & 0.540 & 0.792 & \\
\hline & Mob2 & 0.798 & & & & & & & & & \\
\hline & Mob3 & 0.767 & & & & & & & & & \\
\hline & Mob4 & 0.801 & & & & & & & & & \\
\hline & Mob5 & 0.800 & & & & & & & & & \\
\hline \multirow{5}{*}{$\begin{array}{l}\text { Sense of } \\
\text { Self-Worth }\end{array}$} & SSW1 & 0.724 & 0.897 & 0.635 & 0.685 & 0.647 & 0.394 & 0.768 & 0.724 & 0.595 & 0.797 \\
\hline & SSW2 & 0.792 & & & & & & & & & \\
\hline & SSW3 & 0.813 & & & & & & & & & \\
\hline & SSW4 & 0.852 & & & & & & & & & \\
\hline & SSW5 & 0.798 & & & & & & & & & \\
\hline
\end{tabular}


examining the composite reliability with the threshold values that are greater than 0.7 for all the constructs ? $^{2}$.

All AVE are greater than the threshold values 0.5 2\% Thus, this research model indicates a high level of internal consistency. Convergent validity was tested by means of bootstrapping with cross loading values for all constructs greater than 0.7 , which meets the criteriag? Thus, our research model has sufficient convergent validity.

Discriminant validity was tested with the value of the square roots of the AVE, which are required to be greater than the values of cross-correlated constructs. The results of the square roots of the AVE in our research are found to be great enough as required and therefore our research model has sufficient discriminant validity.

\subsection{Structural Model}

The capability of explanation of research model is determined by $\mathrm{R}^{2}$ in PLS analysis and the value of $\mathrm{R}^{2}$ should be greater than 0.1 . Results of this research show that $\mathrm{R}^{2}$ values are $61.5 \%$ and $15.8 \%$ respectively is shown in Figure 2.

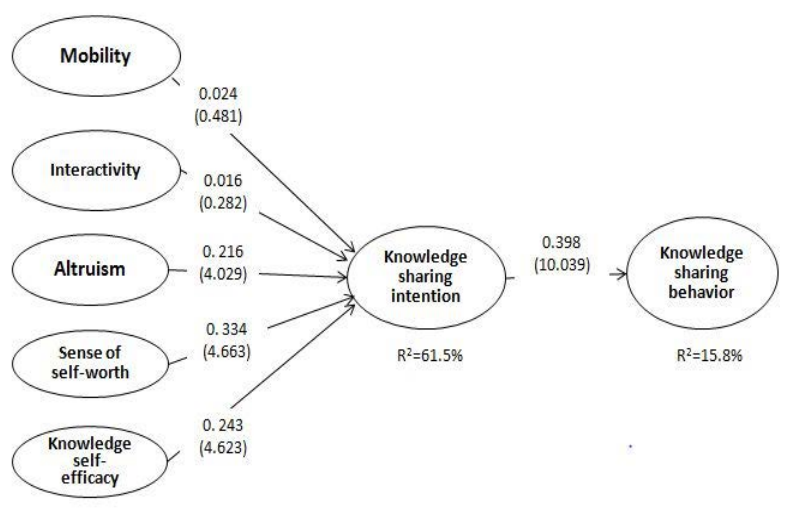

Figure 2. The result of structural model analysis.
One of the two $\mathrm{R}^{2}$ values in our research is $61.5 \%$, which can be considered satisfactory and the other one is $15.8 \%$, which is at an acceptable level. Also examined the path coefficients using bootstrapping and the T-values are calculated.

As reported in Table 2, the impact of constructs mobility and interactivity are 0.481 and 0.282 . Therefore, these two types of hypothesis were rejected. The impact of constructs altruism, sense of self-worth and knowledge self-efficacy are 4.029, 4.663 and 10.039 respectively, thus these hypotheses are supported.

\section{Conclusion}

\subsection{Discussion}

The objective of this study has been to explore the motivations of the Wechat users from the perspectives of media and psychological features in knowledge sharing activities. First we discuss the factors influencing the intention and behaviors in knowledge sharing. The factors include mainly two groups, the first group includes mobility and interactivity, which is related with Wechat media feature and the other group includes altruism, sense of self-worth and knowledge self-efficacy, which is related with users' psychological features.

Mobility and interactivity: The hypotheses arguing the link between expected relationship was not supported. Our findings suggest that Wechat users are careless about the convenience of using mobile device when sharing information. What motivates the users to share knowledge is the value they believe the knowledge creates.

Altruism: Based on our findings, altruism significantly affects Wechat users in KSI and KSB. Users with higher altruism tend to believe the benefits they get from the information will surely benefit others and they would like to share it with others.

Table 2. Hypotheses testing

\begin{tabular}{lccl}
\hline Hypotheses & $\begin{array}{c}\text { Path } \\
\text { coefficient }\end{array}$ & T-value & Result \\
\hline H1: Mobility $\rightarrow$ KSI (Knowledge sharing intention) & 0.024 & 0.481 & not supported \\
H2: Interactivity $\rightarrow$ KSI (Knowledge sharing intention) & 0.016 & 0.282 & not supported \\
H3: Altruism $\rightarrow$ KSI (Knowledge sharing intention) & 0.261 & 4.029 & supported \\
H4: Sense of Self-worth $\rightarrow$ KSI (Knowledge sharing intention) & 0.334 & 4.663 & supported \\
H5: Knowledge sharing-efficacy $\rightarrow$ KSI (Knowledge sharing intention) & 0.243 & 4.623 & supported \\
H6: KSI (Knowledge sharing intention) $\rightarrow$ KSB (Knowledge Sharing & 0.398 & 10.039 & supported \\
Behavior) & & & \\
\hline
\end{tabular}


Sense of self-worth: Based on the results, we suggest that when Wechat users perceived that they are valuable in helping others, they feel enjoyable. Therefore, Wechat users with higher level of sense of self-worth actively take part in knowledge sharing activities because they believe this reflects their own values.

Knowledge self-efficacy: Based on the results, we found that Wechat users with higher level of knowledge self-efficacy have tendency to share knowledge with Wechat friends. They are confident with what they know or what capabilities they have and they believe they are capable of creating values based on their capabilities.

\subsection{Implication and Future Research}

With the development of mobile and telecommunication technology, more and more people rely on mobile devices to deal with problems related with work, learning or keeping in touch with other people. This change of lifestyle make it critical for us to think about how to get accustomed to new lifestyles and find solutions to enhance efficiencies in all facets. One of the changes of information acquiring activity is media users are relying more on mobile technology than before and this enable those to take advantages of fragmented time to deal with information.

This research complements prior research that studied knowledge sharing behaviors based on PC thus provides new horizons for people's knowledge sharing behaviors on mobile device. This research also complements to e-learning related research by looking at the Wechat users' psychological factors of their effects on shaping knowledge sharing behaviors.

For instance, academic institutions may create high quality education contents to provide to students. Firms may also benefit from these active mobile device users. Good products may go viral if customers feel its high value mobile devices by providing valuable product information and this could reduce much cost for advisement.

\section{References}

1. Weixin (fine line) tencent's bringing the mobile IM revolution to the mainstream [Internet]. 2011 [cited 2011 Dec 7]. Available from: http://www.techrice.com.

2. Mallat N, Rossi M, Tuunainen VK, Oorni A. An empirical investigation of mobile ticketing service adoption in public transportation. Personal and Ubiquitous Computing. 2008 Jan; 12(1):57-65.
3. Fang YH, Chiu CM. In justice we trust: exploring knowledge-sharing continuance intentions in virtual communities of practice. Computers in Human Behavior. 2010 Mar; 26(2):235-46.

4. Steuer J. Defining virtual reality: dimensions determining telepresence. Journal of Communication. 1992; 42(4):73-93.

5. Wu G. Conceptualizing and measuring the perceived interactivity of websites. Journal of Current Issues and Research in Advertising. 2006; 28(1):87-104.

6. Mazzolini M, Maddison S. When to jump. In: the role of the instructor in online discussion forums. Computers and Education. 2007 Sep; 49(2):193-213.

7. Kapur M, Kinzer C. Examining the effect of problem type in a synchronous Computer-Supported Collaborative Learning (CSCL) environment. Educational Technology Research and Development. 2007 Oct; 55(5):439-59.

8. Deighton JA. The future of interactive marketing. Harvard Business Review. 1996 Nov-Dec; 74(6):151-61.

9. Hoffman DL, Novak TP. Marketing in hypermedia computer-mediated environments: conceptual foundations. Journal of Marketing. 1996 Jul; 60(3):50-68.

10. Fehr E, Gächter S. Fairness and retaliation: the economics of reciprocity. The Journal of Economic Perspectives. 2000; 14(3):159-81.

11. Crocker J, Wolfe CT. Contingencies of self-worth. Psychological Review. 2001 Jul; 108(3):593-623.

12. Rosenberg M. Conceiving the self. Basic Books: New York; 1979.

13. Becerra-Fernandez I, Sabherwal R. Organizational knowledge management: a contingency perspective. Journal of Management Information Systems. 2001; 18(1):23-55.

14. Lee JN. The impact of knowledge sharing, organizational capability and partnership quality on Information Systems (IS) outsourcing success. Information and Management. 2001 Apr; 38(5):323-35.

15. Constant D, Sproull L, Kiesler S. The kindness of strangers: the usefulness of electronic weak ties for technical advice. Organization Science. 1996 Mar-Apr; 7(2):119-35.

16. Bandura A. Social foundations of thought and action: a social cognitive theory. Prentice-Hall: Englewood Cliffs, New Jersey; 1986.

17. Bordia P, Irmer BE, Abusah D. Differences in sharing knowledge interpersonally and via databases: The role of evaluation apprehension and perceived benefits. European Journal of Work and Organizational Psychology. 2006; 15(3):262-80.

18. Liao C, To P, Hsu F. Exploring knowledge sharing in virtual communities. Online Information Review. 2013; 37(6):891-909.

19. Kakihara M, Sorensen C. Expanding the 'mobility' concept. Association for Computing Machinery (ACM) Special Interest Group on Groupwork (SIGGROUP) Bulletin. New York. 2001; 22(3):33-7.

20. Kaigin B, Basoglu N. Adoption factors of mobile services. International Conference on Mobile Business. Copenhagen; 2006 Jun. p. 1-41. 
21. Davenport TH, Prusak L. Working knowledge: how organizations manage what they know. $2^{\text {nd }}$ edition. Harvard Business Review Press: New York; 2000.

22. Bezjian A, Alexa B, Calder DL. New media interactive advertising vs. traditional advertising. Journal of Advertising Research. 1998 Aug; 38(4):23-32.

23. Hung SY, Durcikova A, Lai HM, Lin WM. The influence of intrinsic and extrinsic motivation on individuals' knowledge sharing behavior. International Journal of $\mathrm{Hu}$ man-Computer Studies. 2011 Jun; 69(6):415-27.

24. Ajzen I, Fishbein M. Understanding attitudes and predicting social behavior. Prentice-Hall: Englewood Cliffs, New Jersey; 1980.

25. Chen CM, KinShuk LJC. Examining the factors influencing participants' knowledge sharing behavior in virtual learning communities. Journal of Educational Technology and Society. 2009; 12(1):134-48.
26. Lin HF, Lee GG. Perceptions of senior managers toward knowledge-sharing behavior. Management Decision. 2004; 42(1):108-25.

27. Hair JF, Black WC, Babin BJ, Anderson RE. Multivariate data analysis, upper saddle river. Pearson Prentice Hall: New Jersey; 2009.

28. Chin WW, Gopal A. Adoption intention in GSS: relative importance of beliefs. Database for Advances in Information Systems. 1995 May-Aug; 26(2-3):42-64.

29. Fornell C, Larcker DF. Evaluating structural equation models with unobservable variables and measurement error. Journal of Marketing Research. 1981 Feb; 18(1):39-50.

30. Falk RF, Miller NB. A primer for soft modeling. The University of Akron Press: Ohio; 1992. 